\title{
J.S. Bach'ın BWV 784 La Minör Envansiyon Adlı Müzik Eserinin Rasyonel Bézier Eğrileri İle Oluşturulan Görsel Modeli
}

\author{
Filiz YAĞCI $^{1 *}$, Rasim Erol DEMİRBATIR ${ }^{2}$, Ridvan EZENTAŞ$^{3}$ \\ ${ }^{1}$ Bursa Uludağ Üniversitesi, Fen-Edebiyat Fakültesi, Matematik Bölümü, Bursa \\ ${ }^{2}$ Bursa Uludağ Üniversitesi, Eğitim Fakültesi, GSB. Müzik Ĕgitimi A.B.D, Bursa \\ ${ }^{3}$ Bursa Uludağ Üniversitesi, Ĕgitim Fakültesi, Matematik Ĕ̌itimi A.B.D, Bursa \\ (ORCID: 0000-0001-5574-9922) (ORCID: 0000-0002-9472-3001) (ORCID: 0000-0001-8619-8334)
}

\begin{abstract}
Öz
Bézier eğrisi, bilgisayar grafikleri ve ilgili alanlarda sıklıkla kullanılan parametrik eğri biçimidir. Müzik, en temel ögesinden en karmaşı ögesine kadar, çeşitli matematiksel yapıları içermekte olup, müzik ile matematik pek çok açıdan birbiriyle ilişkili iki disiplindir. Müzik eserlerinin matematiksel boyutta kodlanıp incelenmesi, bilgisayar destekli yazılımlar aracılığıyla eserlerin analizlerinin yapılması, farklı yaklaşımların üretilmesi ve disiplinler arası çalışma olanaklarının sağlanması bakımından önemli görülmektedir. Bu çalışmanın amacı, müzik sanatının matematik dehası olarak bilinen en önemli bestecilerinden J.S. Bach'ın BWV 784 la minör iki sesli envansiyonunu meydana getiren seslerin matematiksel kodlama yoluyla Rasyonel Bézier eğrileri kullanılarak görsel modelinin oluşturulmasıdır. Polifonik tarzda bestelenen eseri oluşturan sağ ve sol el partilerinin ses yükseklikleri ile süre değerleri matematiksel olarak kodlanmıştır. $\mathrm{Bu}$ yolla elde edilen verilerin kullanıldığı bilgisayar programı yazılarak, Rasyonel Bézier eğrilerinin görsel modeli oluşturulmuştur.
\end{abstract}

Anahtar kelimeler: Müzik ve Matematik, J.S. Bach, Matematiksel Kodlama, Rasyonel Bézier Eğri.

\section{Visual Model of Bach's BWV 784 La Minör Envansion of Musical Work Formed by Rational Bézier Curves}

\begin{abstract}
The Bézier curve is a parametric curve format commonly used in computer graphics and related fields. Music includes various mathematical structures, from the basic element to the most complex element, and music and mathematics are two related disciplines in many respects. It is considered important in terms of coding and analyzing music works in mathematical dimension, analysis of the works through computer aided software, producing different approaches and interdisciplinary work opportunities. The aim of this study is to form a visual model of Rational Bézier curves by means of mathematical coding of the voices that make up BWV 784 la minor two-voice envansion of J.S. Bach's who is one of the most important composers of music art known as mathematical genius. The sound levels and duration values of the right and left hand parties, which are composed in polyphonic style, are mathematically coded. A visual model of the rational Bézier curves was formed by writing a computer program using the data obtained in this way.
\end{abstract}

Keywords: Music and Mathematics, J.S. Bach, Mathematical Coding, Rasyonel Bézier Curve.

\section{Giriș}

Günümüze kadar birçok filozof, matematik ve müzik insanı tarafından bu iki disiplin arasındaki ilişki üzerine araştırmalar yapılmış, müziğin matematiksel yapısı anlaşılmaya çalışılmıştır. "Genellikle diziler, aralıklar, ritim, ölçü, form, melodi, akorlar, oktav eşdeğerliği, doğuşkanlar, tını, akustik, eşit aralıklı ses sistemi ve akordun alternatif yöntemleri vb gibi bazı müziksel kavramların matematiksel olarak izahı yapılmıştır" [18].

*Sorumlu yazar:gfiliz@uludag.edu.tr

Geliş Tarihi: 25.11.2019, Kabul Tarihi: 08.04.2020 
Müzik ile matematik pek çok açıdan birbiriyle ilişkili iki disiplindir. Bu iki disiplin üzerine ilk akademik çalışmaların MÖ 6. yüzyılda Yunan filozof ve matematikçi Pisagor ile başladığı düşünülmektedir. Pisagor'un seslerin frekansları arasındaki çeşitli sayısal oranları keşfiyle ortaya koyduğu sesler arasındaki ilişkilerin sistematik yapısı, müzik kuramının temelini oluşturmaktadır [16]. Bu da müzik, gizli bir aritmetik alıştırmadır diyen Leibniz' in haklılığını göstermektedir [14].

19. yüzyılda matematikçi J. Fourier tarafından müzikal seslerin niteliği incelenmiş, insandan ve müzik aletinden çıkan seslerin matematiksel ifadelerle tanımlanabileceğini göstermiştir. Çıkan seslerin bir sinüs fonksiyonu ile ifade edilebileceğini ispatlamıştır [14]. Piyano tuşları İtalyan matematikçi L. Fibonacci'nin oluşturduğu Fibonacci dizisi $(1,1,2,3,5,8,13,21,34, \ldots)$ ile müzik arasındaki bağlantının görsel açıklamasına olanak sağlar [12]. "Fibonacci dizisinde ardışık iki sayının oranı yaklaşık olarak $\mathrm{Q}=1.61804$ olarak hesaplanır ve bu değere Altın Oran denir. Altın Oran uyum ve güzellik ölçütü olarak sanat ve estetiğin vazgeçilmez kriterlerinden biridir. Ayrıca Mozart, Beethoven, Bach, Chopin, Bela Bartok gibi birçok ünlü bestecinin eserlerinde Fibonacci Dizisi ve Altın Oran'ı kullandığı varsayılmış ve ispat edilmeye çalışılmıştır. Örneğin Mozart Sonatı'ndaki No1.K.279, No2.K.280, No7.K.309, No10.K.330, No15.K.545, No16.K.570 eserlerinde Altın Oran'1 kullandığ ispatlanmıştır. Bunun yanında, Fibonacci dizisini bilinçli olarak kullanan ve bunu belirten besteciler de bulunmaktadır" [13]. B. Taylor, titreşimi temsil eden bir diferansiyel denklem çözümünün bir sinus eğrisi olduğunu bulmuştur. D'Alembert ve L. Euler gibi matematikçiler titreşim dizisini bir diferansiyel denklem olarak ifade etmişler ve J. B. Fourier, titreşim dalgalarını trigonometrik fonksiyonları kullanarak tanımlamıştır [6]. 1869'da, müzik teorisyeni A.V. Oettingen, 20. yüzyılın müzik dünyasında, çığır açtığı harmoniklik teorisini kurmuştur [14]. Mandelbrot, (1983) birçok bilim dalında kullanılan fraktal geometrisini tanımlamıştır. Campbell (2004) ve Wright (2009) fraktal geometrisini müzikte ilk kullanmışlardır $[5,19]$.

Bilgisayar ile geometrik modelleme yöntemlerinin kullanımı son yirmi yılda büyük bir hızla ilerlemektedir. Bilgisayar destekli olarak yapılan tasarım, yapının görsel olarak sunulmasını, veri hazırlanmasını, analiz yazılımlarının kullanılmasından sonra sonuçların değerlendirilmesini ve bilgisayar destekli üretimde kullanılmasını sağlar. Genel olarak iki boyutlu (2D) geometrik eğri modelleme ve üç boyutlu (3D) geometrik yüzey modelleme, bilgisayar grafikleri, bilgisayar destekli tasarım ve üretim teknolojileri alanlarının hızlı bir şekilde gelişmesinde temel etkenlerden biridir.

Bézier eğrisi ilk olarak Paul de Casteljau (1959) tarafindan ileri sürülmüştür. Fransız mühendis Pierre Bézier (1974), tarafından otomobillerin tasarımında kullanılmasıyla tanınmıştır. Bézier eğrisi ile yüzeylerin tasarımı ve programlanması daha kolay hale gelmiştir. Bu tür özelliklerinden dolayı Bézier eğrisi, şimdilerde vektör temelli çizim, font tasarımı, endüstriyel ve bilgisayar destekli tasarım, ve 3D modelleme gibi bir çok alanda kullanılmaktadır [10]. Battey (2004), perde-sürekli melodik ekspresyonlar ve süslemelerin bezier spline modellemesini incelemiştir. Bu çalışmasında sürekli ekspresyon verilerinin Bezier eğri modellemesi, ister analitik ister kompozisyon amaçlı olsun, perdesürekli melodik malzemelerin manipüle edilmesi ve işlenmesi zorluğunun ele alınması için uygun bir araç sağladığı sonucuna varmıştır [1].

Johann Sebastian Bach (1685-1750) dünyaca ünlü Alman barok müzik bestecisi ve orgcusudur. Envansiyon 'buluş' anlamına gelmektedir. Kısa bir form türü olarak envansiyon, kontrpuan biçiminin özgürce işlenmesi ile bestelenir. Kontrpuan yöntemiyle yazılan büyük füg formunun hazırlayıcısı olarak tanımlanabilir. Her biri farklı yapıda olan envansiyona taklitli yazı hâkimdir. Envansiyon formunda birden fazla motif, ara müziklerle tonal ilişkileri ve geçişleri kurar. [8]'de envansiyon, bir müzikal fikrin veya motifin serbest kontrpuan kurallarına göre işlenmesidir. Bu kısa form Bach'la doruğa ulaşmıştır. Polifonik türün en sade ve gevşek dokudaki yazısı olan envansiyonda motifin işlenmeye uygun yapıda ve tonaliteyi belirtecek niteliklere sahip olması gerekir. Motif, her ses partisinde tekrarlanır ve taklit edilir. Motifle birlikte kontrpuntal bir eşlik partisi vardır. Motifin bulunmadığı yerlerde ara müziği yer alır.

“Bach'ın 1723 yılında, Köthen yıllarında bestelediği iki ve üç sesli envansiyonlar, çoğunlukla eğitime yöneliktir. Bu envansiyonlar, 'Aufrichtige Anleitung' (Doğru Yönlendirme) başlığıyla 30 ayrı parçadan oluşmaktadır. Parçalar, teknik becerinin gelişimi için bestelenmiştir. Envansiyon kolay bir biçim olarak görünse de, aslında gelecek zor eserlere hazırlık olarak tasarlanmıştır. Bu parçaların 15'i iki sesli, 15'i ise üç seslidir. İki ve üç sesli envansiyonlarda tonalite düzeni aynıdır ve do majör-do minör; re majör-re minör; mi bemol majör- mi minör; fa majör-fa minör; sol majör-sol minör; la majör-la minör; si bemol majör-si minör dizilimiyle yazılmıştır" [3]. "Eserler incelendiğinde her birinin çok farklı bir 
yapıya sahip olduğu görülür. Her parçada motiflerin, ara müziklerin ve tonal ilişkilerin oluşturduğu kurgu birbirinden farklıdır. Envansiyon olgusu, çalma tekniğindeki buluşlarla sınırlı kalmayıp, sanki her parçanın yapısal özelliklerinde de gizli gibidir" [6]. Çokseslilik (polifoni), kanonik yapı, birden fazla süsleme ve motifin eşzamanlı yer alması, bestecinin üslupsal özelliğini ortaya koymaktadır.

Bilgisayarlar ile geometrik modelleme yöntemlerinin kullanımı son yirmi yılda büyük bir hız ile ilerlemektedir. Birçok materyalin geometrik modelinin oluşturulmasında Bézier eğri ve yüzey modelleme yöntemlerinin kullanıldığı bilinmektedir [8]. Müzik eserlerinin matematiksel boyutta kodlanıp incelenmesi, bilgisayar destekli yazılımlar aracılığıyla eserlerin analizlerinin yapılması, farklı yaklaşımların üretilmesi ve disiplinler arası çalışma olanaklarının sağlanması bakımından yararlı görülmektedir. $\mathrm{Bu}$ anlamda soyut boyutta olan seslerin geometrik ortama aktarilarak somut hale dönüştürülmesi, eserleri oluşturan seslerin yükseklik ve süre değerlerinin farklı kombinasyonlarda ele alınarak yapısal analizlerinin gerçekleştirilme çalışmaları yenilikçi bir yaklaşım olarak görülmektedir. Bu çalışmada, J.S. Bach'ın piyano için yazdığ BWV 784 la minör iki sesli envansiyonunu meydana getiren seslerin matematiksel kodlama yoluyla Rasyonel Bézier eğrileri kullanılarak görsel modelinin oluşturulması ve bu modelle eserin sağ ve sol partilerinin ses yükseklik değerleri ile süre değerleri ve kullanım sayılarına uyumlu grafiği çizilmesi amaçlanmıştır.

\section{Materyal ve Metot}

$\mathrm{Bu}$ çalışmada seçilen eserin nota ses yükseklikleri ve nota ses sürelerinin matematiksel kodları kullanılarak Rasyonel Bézier eğrileri tasarlama yöntemi ile görsel model oluşturulmuştur. Çalışma verileri eserin bütününü oluşturan sağ ve sol el partilerinde yer alan seslerin yükseklik ve süre değerleriyle elde edilmiştir. Bilgisayar grafiklerinin önemli bir uygulaması olan Bézier eğrisi, poligonun köşeleri ile birebir ilişkilidir. Poligonunda sadece ilk ve son köşeleri eğri üzerinde bulunur ve diğer köşeler ise eğrinin şeklini ve derecesini tanımlamaktadır. Bézier eğrisi açık veya kapalı poligon olarak tanımlanabilir. Burada poligonların kontrol noktalarındaki değişiklikler eğrideki değişikliğe neden olmaktadır. Kullanıcı köşelerin kullanımı sayesinde görsel olarak ulaşabileceği sonuçları önceden fark edebilmektedir [8]. Şekil 1'de gösterildiği gibi, Bézier eğrileri kontrol noktalarını içeren bir konveks çokgen içerisinde tanımlı Bernstein polinomlarından oluşan parametrik bir eğri çeşididir. Tasarımda kullanım kolaylığı açısından oldukça yaygın bir biçimde tercih edilen Bézier eğrileri içinde bulundukları konveks çokgenin başlangıç ve bitiş noktalarının değiş̧irilmesi ile eğrinin genel olarak değişimini sağlamaktadır. Bu nedenle Bézier eğrisinin uç noktalarındaki teğet ve eğrilik hesapları geometrik açıdan önemlidir.

Bézier eğrileri, girdi olarak kullanılan kontrol noktaları ve bir dizi polinom fonksiyonlarıyla tanımlanır. $\mathrm{n}$. dereceden, $\mathrm{n}+1$ adet $B_{i}$ kontrol noktasına sahip bézier eğrisinin parametrik denklemi; Bernstein polinomları olarak bilinen katsayılar $J_{n, i}(t)=\left(\begin{array}{c}n \\ i\end{array}\right) t^{i}(1-t)^{n-i}$ olmak üzere,

$\mathrm{P}(t)=(X(t), Y(t))=\sum_{i=0}^{n} B_{i} J_{n, i}(t), 0 \leq \mathrm{t} \leq 1$

şeklinde tanımlanır. Bézier eğrisi üzerindeki herhangi bir noktanın koordinatı,

$x(t)=\sum_{i=0}^{n} x_{i} J_{n, i}(t), y(t)=\sum_{i=0}^{n} y_{i} J_{n, i}(t)$

formülleri ile hesaplanır [17].
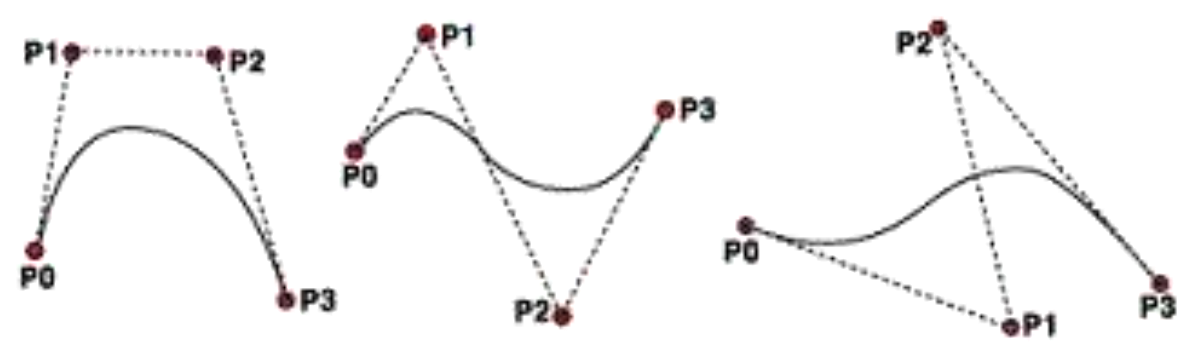
Şekil 1. Bézier Eğrilerine Örnekler

Rasyonel Bézier eğrileri, konik kesitlerin incelenmesinde pratik kullanımı açısından oldukça avantajlı bir eğri üretme tekniğidir [8]. Şekil 2'de görüldüğü gibi hepsi birden sıfir olmayan $w_{i}$ skaler ağırlıklı n. dereceden Rasyonel Bézier eğrisi

$P(t)=(x(t), y(t))=\frac{\sum_{i=0}^{n} B_{i} J_{n, i}(t) w_{i}}{\sum_{i=0}^{n} w_{i} J_{n, i}(t)}$

şeklinde tanımlanır.

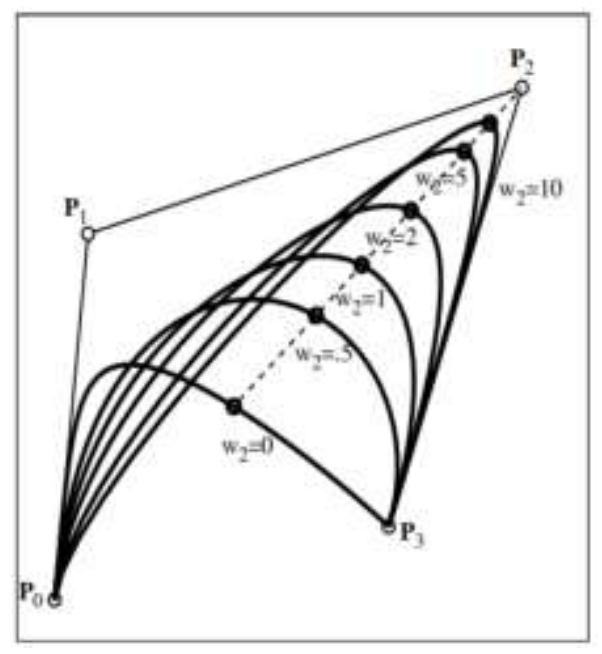

Şekil 2. Rasyonel Bézier eğrisi

Bilgisayar destekli geometrik modelleme yöntemleri vasıtasıyla, eğri veya yüzey oluşturmak için matematiksel ifadeleri ve bunların uygulanması için gerekli algoritmalar mevcuttur. Bilgisayar destekli olarak yapılan tasarım bize tasarımın görsel olarak sunulmasını, veri hazırlanmasını, analiz yazılımlarının kullanılmasından sonra sonuçların değerlendirilmesini sağlamaktadır. Rasyonel Bézier eğrileri tasarlama yöntemi öncelikle kontrol noktaları seçilir. İlk ve son kontrol noktası, eğrinin başlangıç ve bitiş noktalarını, diğer noktalar ise eğrinin yapısını belirlemek için kullanılır. Bu kontrol noktalarının oluşturduğu poligonsal bölge konveks çokgen (Convex Hull) olarak isimlendirilir. Konveks çokgenin bir köşesinin konumu değiştirildiğinde eğrinin tümü değil sadece belli bir kısmı değişir. Daha sonra belirlenen kontrol noktalarıyla Rasyonel Bézier eğrilerinin parametrik denklemi bulunur. Denklemi bulunan bu eğrinin görsel modeli bir programlama dili aracılığıyla oluşturulur [8].

Bach'ın BWV 784, la minör iki sesli envansiyonun temel motifi, iki vuruş boyunca onaltılık notalardan oluşmaktadır. İlk ölçüde görülen A motifi ve üçüncü ölçüden itibaren motifin hareketleriyle oluşan B motifi hemen hemen eserin sonuna kadar duyulmaktadır. Arada olan diğer kontrpuan partileri figür oluşturarak temaları birbirine bağlar. Bu envansiyonun her kesitinde motiflerin düzeni, sol el ve sağ el paylaşımı açısından bir düzen oluşturur ve kendi içerisinde bir kurgu yaratır. Eser boyunca bu iki parti, sürekli olarak işlenir ve birbirini taklit eder [3].

$\mathrm{Bu}$ çalışmanın verileri, seçilen müzik eserinin ses yükseklik ve nota ses süre değerlerinin kodlama tabloları yardımıyla matematiksel ortama aktarılmasıyla elde edilmiş̧ir. Eseri oluşturan sesler $[-39,49]$ aralığında ve seslerin nota çalınma süre değerleri [1,32] aralığında tanımlanmıştır. Eseri oluşturan seslerin kodlamaları sağ ve sol el partileri için ayrı ayrı yapılmış, SPSS istatistik programı yardımıyla elde edilen verilerin çapraz tabloları oluşturulmuştur. Sağ ve sol el partileri için çapraz tablolar Tablo 1 ve Tablo 2'de verilmiştir. 
Tablo 1. Eserin sağ el partisinin ses yükseklik ve süre değerlerinin çapraz tablosu

\begin{tabular}{|c|c|c|c|c|c|}
\hline \multirow{2}{*}{$\begin{array}{l}\text { Sağ el partisi ses } \\
\text { yükseklik değerleri }\end{array}$} & \multicolumn{3}{|c|}{ Sağ el partisi ses süre değerleri } & \multicolumn{2}{|c|}{ Toplam } \\
\hline & 4 & 8 & 16 & $\mathrm{~N}$ & $\%$ \\
\hline-6 & 0 & 0 & 1 & 1 & 0,3 \\
\hline-4 & 0 & 1 & 0 & 1 & 0,3 \\
\hline-3 & 1 & 0 & 3 & 4 & 1,2 \\
\hline-1 & 0 & 0 & 2 & 2 & 0,6 \\
\hline 0 & 3 & 6 & 13 & 22 & 6,6 \\
\hline 1 & 0 & 0 & 7 & 7 & 2,1 \\
\hline 3 & 0 & 1 & 4 & 5 & 1,5 \\
\hline 4 & 0 & 0 & 2 & 2 & 0,6 \\
\hline 5 & 0 & 4 & 17 & 21 & 6,3 \\
\hline 6 & 0 & 2 & 6 & 8 & 2,4 \\
\hline 7 & 0 & 0 & 5 & 5 & 1,5 \\
\hline 8 & 0 & 3 & 9 & 12 & 3,6 \\
\hline 9 & 0 & 3 & 7 & 10 & 3,0 \\
\hline 10 & 0 & 4 & 26 & 30 & 9,0 \\
\hline 12 & 0 & 3 & 32 & 35 & 10,6 \\
\hline 13 & 0 & 8 & 33 & 41 & 12,4 \\
\hline 14 & 0 & 0 & 2 & 2 & 0,6 \\
\hline 15 & 0 & 3 & 34 & 37 & 11,2 \\
\hline 16 & 0 & 0 & 4 & 4 & 1,2 \\
\hline 17 & 0 & 9 & 24 & 33 & 10,0 \\
\hline 18 & 0 & 1 & 12 & 13 & 3,9 \\
\hline 19 & 0 & 2 & 5 & 7 & 2,1 \\
\hline 20 & 0 & 5 & 10 & 15 & 4,5 \\
\hline 21 & 0 & 0 & 1 & 1 & 0,3 \\
\hline 22 & 0 & 1 & 5 & 6 & 1,8 \\
\hline 23 & 0 & 0 & 1 & 1 & 0,3 \\
\hline 24 & 0 & 1 & 2 & 3 & 0,9 \\
\hline 25 & 0 & 1 & 1 & 2 & 0,6 \\
\hline Toplam & 4 & 58 & 268 & 330 & 100 \\
\hline
\end{tabular}

Tablo 1 incelendiğinde eserin sağ el partisine ait ses yüksekliklerinin tanım aralığı [-6,25] ve toplam 29 adet ses kombinasyonu oluşturularak toplam 330 nota kullanılmıștır. Bu seslerin 268 tanesi 16 'llk, 58 tanesi 8' lik ve 4 tanesi ise 4'luk notalardan oluşmuștur. En yüksek sağ el partisi ses yükseklik değerleri sırasılyla $13,15,12$ ve 17 ve buna karşılık gelen ses sürelerinin frekansları $41(\% 12,4)$, $37(\% 11,2), 35(\% 10,6)$ ve 33(\%10,0) iken en düşük sağ el nota ses yükseklikleri ise $-6,-4,21$ ve 23 ve buna karşılık gelen ses sürelerinin frekansı 1(\%0,3) olduğu görülmektedir. Şekil 3'de eserin ağ el partisi ses yükseklik ve frekans dağılımı; Şekil 4'de ise sağ el partisi ses yükseklik ve süre değerlerinin dağılımı verilmiştir.

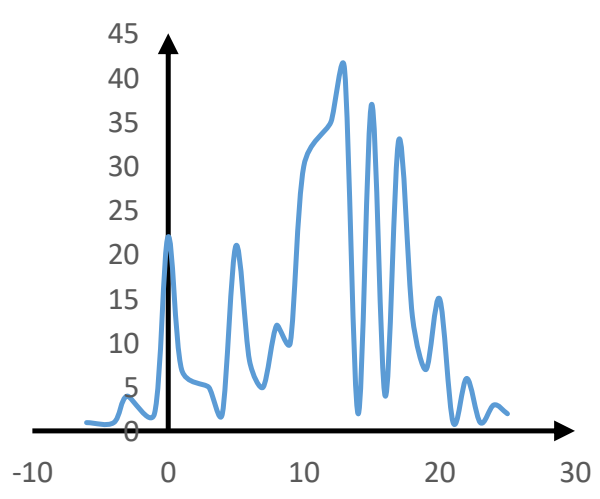

Şekil 3. Sağ el partisi ses yükseklik ve frekans dağılımı

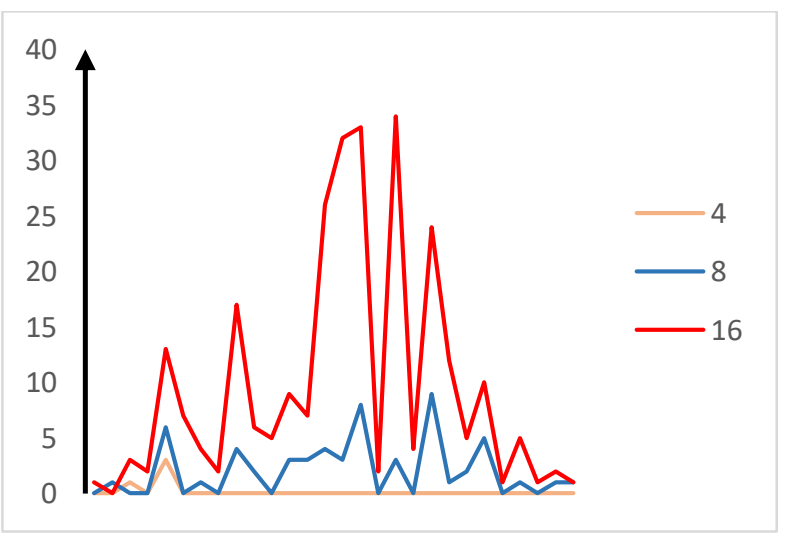

Şekil 4. Sağ el partisi ses yükseklik ve ses süre değerlerinin dağılımı 
Şekil 3'de eserin sağ el partisini oluşturan seslerin yükseklik ve frekans dağılımı görülmektedir. Eserin sağ el partisinde kullanılan toplam 330 notanın ses skalası [-6,25] aralığındaki seslerden oluşmakta iken kullanım sıklığı en yüksek değer 41, en düşük değer ise 1'dir. Şekil 4'de bir önceki grafikte yer alan ses yüksekliklerine göre ses sürelerinin dağ 1 lımı görülmektedir. Eserin 16'llk ses süre değerinin 268 defa, 8 'lik ses süre değerinin 58 defa ve dörtlük ses süre değerinin 4 defa kullanıldığ görülmektedir. $\mathrm{Bu}$ durum eserin yoğunlukla $16^{\prime}{ }^{\prime} l \mathrm{k}$ süre değerini içeren seslerle işlendiğini göstermektedir. Buna göre eserin 16'llk ses süre değerinin, ses yükseklik değerleri 1 ile 34 ve 8 'lik ses süre değerinin, ses yükseklik değerleri 1 ile 8 arasında dağglırken, 4'lük ses süre değerinin, ses yükseklik değerleri 0 ile 3 arasında yer almıştır.

Tablo 2. Eserin sol el partisinin ses yükseklik ve süre değerlerinin çapraz tablosu

\begin{tabular}{|c|c|c|c|c|c|}
\hline \multirow{2}{*}{$\begin{array}{l}\text { Sol el partisi ses } \\
\text { yükseklik değerleri }\end{array}$} & \multicolumn{3}{|c|}{ Sağ El Ses Süreleri } & \multicolumn{2}{|c|}{ Toplam } \\
\hline & 4 & 8 & 16 & $\mathrm{~N}$ & $\%$ \\
\hline-22 & 0 & 2 & 0 & 2 & 0,7 \\
\hline-21 & 0 & 2 & 0 & 2 & 0,7 \\
\hline-20 & 0 & 4 & 0 & 4 & 1,4 \\
\hline-19 & 0 & 2 & 0 & 2 & 0,7 \\
\hline-17 & 0 & 1 & 3 & 4 & 1,4 \\
\hline-16 & 0 & 4 & 0 & 4 & 1,4 \\
\hline-15 & 0 & 7 & 2 & 10 & 3,6 \\
\hline-13 & 0 & 8 & 4 & 12 & 4,3 \\
\hline-12 & 0 & 7 & 5 & 12 & 4,3 \\
\hline-11 & 0 & 1 & 0 & 1 & 0,4 \\
\hline-10 & 0 & 5 & 5 & 10 & 3,6 \\
\hline-9 & 0 & 0 & 1 & 1 & 0,4 \\
\hline-8 & 0 & 10 & 13 & 23 & 8,2 \\
\hline-7 & 0 & 3 & 4 & 7 & 2,5 \\
\hline-6 & 0 & 3 & 5 & 8 & 2,9 \\
\hline-5 & 0 & 4 & 13 & 17 & 6,1 \\
\hline-4 & 0 & 8 & 2 & 10 & 3,6 \\
\hline-3 & 2 & 7 & 18 & 27 & 9,3 \\
\hline-2 & 0 & 2 & 0 & 2 & 0,7 \\
\hline-1 & 0 & 7 & 15 & 22 & 7,9 \\
\hline 0 & 1 & 4 & 8 & 13 & 7,9 \\
\hline 1 & 0 & 9 & 21 & 30 & 10,4 \\
\hline 2 & 0 & 0 & 1 & 1 & 0,4 \\
\hline 3 & 0 & 2 & 15 & 17 & 6,1 \\
\hline 4 & 0 & 1 & 1 & 2 & 0,7 \\
\hline 5 & 0 & 3 & 21 & 24 & 7,2 \\
\hline 6 & 0 & 0 & 5 & 5 & 1,8 \\
\hline 7 & 0 & 1 & 4 & 5 & 1,8 \\
\hline 8 & 0 & 1 & 5 & 6 & 2,2 \\
\hline 9 & 0 & 1 & 0 & 1 & 0,4 \\
\hline 10 & 0 & 0 & 1 & 1 & 0,4 \\
\hline Toplam & 3 & 109 & 172 & 285 & 100 \\
\hline
\end{tabular}

Tablo 2'de eserin sol el partisini oluşturan seslerin yüksekliklerinin tanım aralı̆̆ $[-22,10]$ ve toplam 33 adet ses kombinasyonu oluşturularak toplam 285 nota kullanıldığı görülmektedir. $\mathrm{Bu}$ notaların 172 tanesi 16'llk, 109 tanesi 8'lik ve 3 tanesi ise 4'luk notalardan oluşmuştur. En yüksek sol el nota ses değerleri sırasıyla $1,-3$ ve -8 ve buna karşl1ık gelen ses sürelerinin frekansları $30(\% 10,4)$, $27(\% 9,3)$ ve $23(\% 8,2)$ iken; en düşük sol el nota ses yükseklikleri ise $-9,2,9$ ve 10 ve buna karş1l1k gelen ses sürelerinin frekansı $1(\% 0,4)$ olduğu görülmektedir. Eserin sol el partisi ses yükseklik ve frekans dağılımı Şekil 5'de ve sol el partisi ses yükseklik ve ses süre değerlerinin dağılımı Şekil 6'da verilmiştir. 


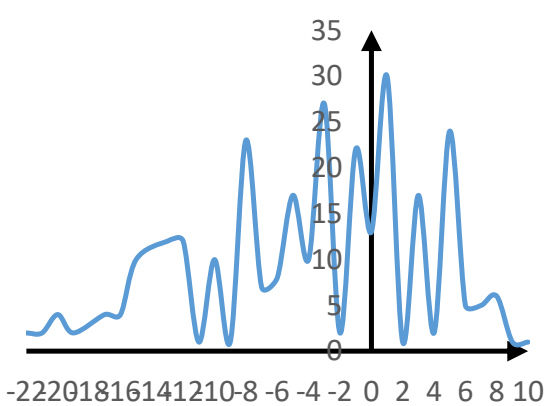

Şekil 5. Sol El Partisi Ses Yükseklik ve Frekans dağılımı

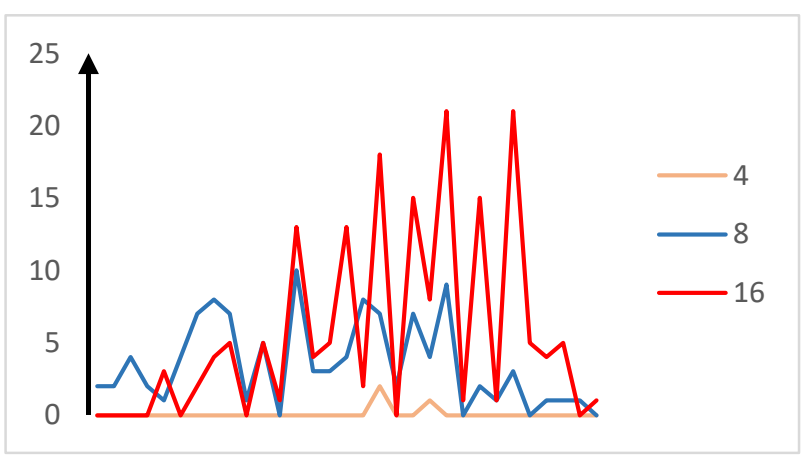

Şekil 6. Sol El Partisi Ses Yükseklik ve Ses Süre dağıllımı

Şekil 5'de eserin sol el partisini oluşturan seslerin yükseklik ve frekans dağılımı görülmektedir. Eserin sol el partisinde kullanılan toplam 285 notanın ses skalası $[-22,10]$ aralığındaki seslerden oluşmakta iken kullanım sıklığı en yüksek değer 21, en düşük değer ise 1'dir. Şekil 6'da bir önceki grafikte yer alan ses yüksekliklerine göre ses sürelerinin dağ 11 lmı görülmektedir. Eserin 16'l1k ses süre değerinin 172 defa, 8'lik ses süre değerinin 109 defa ve dörtlük ses süre değerinin 3 defa kullanıldığ görülmektedir. $\mathrm{Bu}$ durum eserin yoğunlukla 16'llk süre değerini içeren seslerle işlendiğini göstermektedir. Buna göre eserin 16'llk ses süre değerinin, ses yükseklik değerleri 0 ile 21 ve $8^{\prime}$ lik ses süre değerinin, ses yükseklik değerleri 2 ile 10 arasında dağılırken, 4'lük ses süre değerinin, ses yükseklik değerleri 0 ile 2 arasında yer almıştır.

\section{Bulgular ve Tartışma}

$\mathrm{Bu}$ çalışmada bilgisayar destekli eğri tasarımında kullanılan ve $x(t)=\sum_{i=0}^{n} x_{i} J_{n, i}(t), y(t)=$ $\sum_{i=0}^{n} y_{i} J_{n, i}(t)$ ve $P(t)=(x(t), y(t))=\frac{\sum_{i=0}^{n} B_{i} J_{n, i}(t) w_{i}}{\sum_{i=0}^{n} w_{i} J_{n, i}(t)}$ denklemi ile temsil edilen Rasyonel Bézier eğri tasarlama yöntemi kullanılmıştır. Rasyonel Bézier eğri denklemleri birer polinom fonksiyondur. Rasyonel Bézier eğri parametrik denkleminde $x_{i}$, Envansiyonun ses yükseklikleri, $y_{i}$, ses değerleri ve $w_{i}$, ise frekans değerleri ile gösterilmiştir. Seçilen eserin sağ ve sol partilerini temsil eden Rasyonel Bézier eğri denklemini ve grafiklerinin bulmak için de genel amaçlı matematiksel problem çözüm yazılımları içinde matematiksel hesaplama, programlama, modelleme yazılımı olarak dünyaca en güvenilen yazılımlardan biri olan Maple 13 kullanılmıştır. Seçilen eserin kodlamalarına göre Maple 13 için oluşturulan program aşağıda verilmiştir.

\section{$>$ \#Sağ El}

Sağ el partisinin maple programı;

$>\mathrm{k} 1:=\operatorname{Matrix}([[-6,16],[-4,8],[-3,4],[-3,16],[-1,16],[0,4],[0,8],[0,16],[1,16],[3,8],[3,16],[4,16],[5,8],[5,16]$, $[6,8],[6,16],[7,16],[8,8],[8,16],[9,8],[9,16],[10,8],[10,16],[12,8],[12,16],[13,8],[13,16],[14,16],[15,8]$, $[15,16],[16,16],[17,8],[17,16],[18,8],[18,16],[19,8],[19,16],[20,8],[20,16],[21,16],[22,8],[22,16],[23,16]$, $[24,8],[24,16],[25,8],[25,16]]):$

> w1:=Matrix $([[1,1,1,3,2,3,6,13,7,1,4,2,4,17,2,6,5,3,9,3,7,4,26,3,32,8,33,2,3,34,4,9,24,1,12,2,5,5,10,1,1,5$,

$1,1,2,1,1]])$ :

$>\mathrm{m}, \mathrm{n}:=$ Dimension $(\mathrm{k} 1)$ :

$>\mathrm{b}:=\mathrm{m}-1: \mathrm{x}:=0: \mathrm{y}:=0$ :binomx $:=0:$ binomy: $=0$ :

$>$ for i from 0 to $b$ do

$>\mathrm{x}:=\mathrm{x}+\mathrm{w} 1[1, \mathrm{i}+1] *$ binomial $(\mathrm{b}, \mathrm{i}) *\left(\mathrm{t}^{\wedge} \mathrm{i}\right) *(1-\mathrm{t})^{\wedge}(\mathrm{b}-\mathrm{i}) * \mathrm{k} 1[\mathrm{i}+1,1]$ :

$>\mathrm{y}:=\mathrm{y}+\mathrm{w} 1[1, \mathrm{i}+1]^{*}$ binomial $(\mathrm{b}, \mathrm{i}) *\left(\mathrm{t}^{\wedge} \mathrm{i}\right) *(1-\mathrm{t})^{\wedge}(\mathrm{b}-\mathrm{i}) * \mathrm{k} 1[\mathrm{i}+1,2]$ :

$>$ binomx $:=$ binom $x+w 1[1, \mathrm{i}+1]^{*} \operatorname{binomial}(\mathrm{b}, \mathrm{i})^{*}\left(\mathrm{t}^{\wedge} \mathrm{i}\right)^{*}(1-\mathrm{t})^{\wedge}(\mathrm{b}-\mathrm{i})$ :

$>$ binomy:=binomy+w $1[1, \mathrm{i}+1]^{*} \operatorname{binomial}(\mathrm{b}, \mathrm{i})^{*}\left(\mathrm{t} \mathrm{t}^{\wedge}\right)^{*}(1-\mathrm{t})^{\wedge}(\mathrm{b}-\mathrm{i})$ :

$>$ end do:

$>\mathrm{x} 1:=\mathrm{x} /$ binomx:

$>\mathrm{y} 1:=\mathrm{y} / \mathrm{binomy:}$

$>$ egri1:=plot $([\mathrm{x} 1(\mathrm{t}), \mathrm{y} 1(\mathrm{t}), \mathrm{t}=0 . .1]$, color=green, thickness=1, scaling=CONSTRAINED):

$>\mathrm{k} 1 \_$poligon:=plot $(\mathrm{k} 1$, scaling=CONSTRAINED $)$ :

$>$ display(\{egri1,k1_poligon $\})$; 
olup, bu programın çalıştırılması ile elde edilen ve sağ el partisini temsil eden Rasyonel Bézier eğrisinin parametrik denklemleri:

$$
\begin{aligned}
& x(t)=\frac{a_{1}(1-t)^{44}+a_{2} t(1-t)^{43}+a_{3} t^{2}(1-t)^{42}+\ldots+a_{43} t^{43}(1-t)+a_{44} t^{44}}{b_{1}(1-t)^{44}+b_{2} t(1-t)^{43}+b_{3} t^{2}(1-t)^{42}+\ldots+b_{43} t^{43}(1-t)+b_{44} t^{44}} \\
& y(t)=\frac{c_{1}(1-t)^{44}+c_{2} t(1-t)^{43}+c_{3} t^{2}(1-t)^{42}+\ldots+c_{43} t^{43}(1-t)+c_{44} t^{44}}{d_{1}(1-t)^{44}+d_{2} t(1-t)^{43}+d_{3} t^{2}(1-t)^{42}+\ldots+d_{43} t^{43}(1-t)+d_{44} t^{44}}
\end{aligned}
$$

şeklinde bulunmuş ve bu denklemlerin oluşturduğu eğrinin grafiği Şekil 7'de verilmiştir. Burada katsayılar büyük reel sayılardan oluşması nedeniyle $a_{1}, a_{2}, a_{3}, \ldots, a_{43}, a_{44}, b_{1}, b_{2}, b_{3}, \ldots, b_{43}, b_{44}$, $c_{1}, c_{2}, c_{3}, \ldots, c_{43}, c_{44}, d_{1}, d_{2}, d_{3}, \ldots, d_{43}$ ve $d_{44}$ şeklinde alfabetik olarak yazımı tercih edilmiştir.

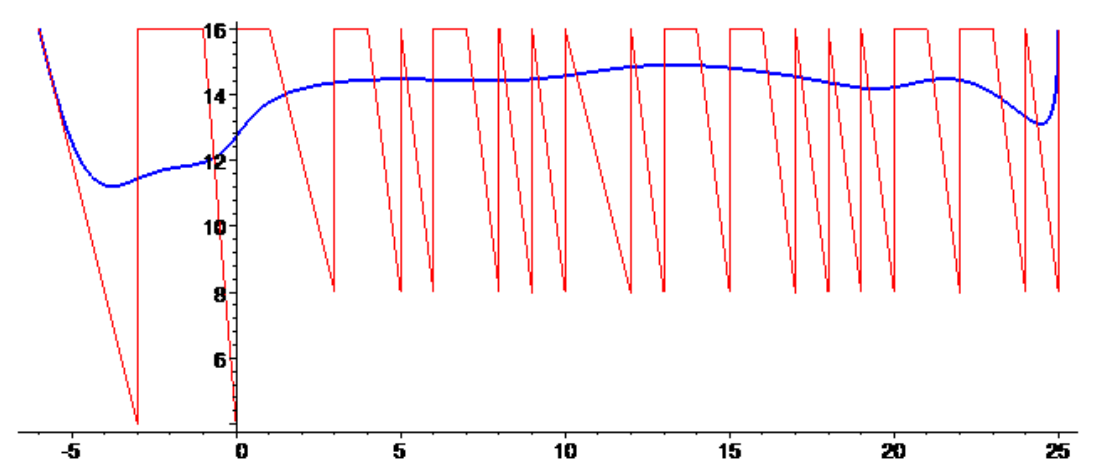

Şekil 7. Bach’ın İki Sesli Envasiyonunun Sağ Partisinin Rasyonel Bézier Eğrisinin Görsel Modeli

Parametrik denklemleri 44. dereceden birer eğrisinin grafiğgi Şekil 7' de çizilmiştir. Bu eğrinin x ekseni tanım aralığı $[-6,25]$ olan sağ el nota yükseklikleri, y ekseni ise sağ el ses süreleri ile kodlanmıştır. Grafikte anlaşıldığı gibi eserde $\quad[-6,-1]$ aralığında kullanılan pes seslerin $[1,25]$ aralığında tiz seslere daha az kullanıldığı tespit edilmiştir. Bulunan Rasyonel Bézier eğrisinin grafiği aracılığıyla sağ partinin görsel modelinin oluşturulmuştur.

\section{$>$ \#Sol El}

Envansiyonun sol partisinin maple programı;

$>$ k2:=Matrix([[[-22,8],[-21,8],[-20,8],[-19,8],[-17,8],[-17,16],[-16,8],[-15,8],[-15,16],[-13,8], [-13,16], [-12,8], [$12,16],[-11,8],[-10,8],[-10,16],[-9,16],[-8,8],[-8,16],[-7,8],[-7,16],[-6,8],[-6,16],[-5,8],[-5,16],[-4,8],[-4,16],[-$ $3,4],[-3,8],[-3,16],[-2,8],[-1,8],[-1,16],[0,4],[0,8],[0,16],[1,8],[1,16],[2,16],[3,8],[3,16],[4,8],[4,16]$, $[5,8],[5,16],[6,16],[7,8],[7,16],[8,8],[8,16],[9,8],[10,16]]]):$

> w2:=Matrix[2,2,4,2,1,3,4,7,2,8,4,7,5,1,5,5,1,10,13,3,4,3,5,4,13,8,2,2,7,18,2,7,15,1,4,8,9,21,1,2,15,1,1,3,21,5,1,

$4,1,5,1,1]])$ :

$>\mathrm{m}, \mathrm{n}:=\operatorname{Dimen} \operatorname{sion}(\mathrm{k} 2): \mathrm{b} 2:=\mathrm{m}-1: \mathrm{x}:=0: \mathrm{y}:=0$ :binomx:=0:binomy: $=0$ :

$>$ for i from 0 to $b 2$ do

$>\mathrm{x}:=\mathrm{x}+\mathrm{w} 2[1, \mathrm{i}+1]^{*}$ binomial $(\mathrm{b} 2, \mathrm{i})^{*}\left(\mathrm{t}^{\wedge} \mathrm{i}\right) *(1-\mathrm{t})^{\wedge}(\mathrm{b} 2-\mathrm{i}) * \mathrm{k} 2[\mathrm{i}+1,1]$ :

$>\mathrm{y}:=\mathrm{y}+\mathrm{w} 2[1, \mathrm{i}+1]^{*} \operatorname{binomial}(\mathrm{b} 2, \mathrm{i})^{*}\left(\mathrm{t}^{\wedge} \mathrm{i}\right)^{*}(1-\mathrm{t})^{\wedge}(\mathrm{b} 2-\mathrm{i})^{*} \mathrm{k} 2[\mathrm{i}+1,2]$ :

$>$ binomx:=binomx $+\mathrm{w} 2[1, \mathrm{i}+1]^{*} \operatorname{binomial}(\mathrm{b} 2, \mathrm{i})^{*}\left(\mathrm{t}^{\wedge} \mathrm{i}\right)^{*}(1-\mathrm{t})^{\wedge}(\mathrm{b} 2-\mathrm{i})$ :

$>$ binomy:=binomy+w2[1,i+1]*binomial $(\mathrm{b} 2, \mathrm{i}) *\left(\mathrm{t}^{\wedge} \mathrm{i}\right) *(1-\mathrm{t})^{\wedge}(\mathrm{b} 2-\mathrm{i})$ :

$>$ end do:

$>\mathrm{x} 2:=\mathrm{x} /$ binomx:

$>$ y2:=y/binomy:

$>$ egri2:=plot $([\mathrm{x} 2(\mathrm{t}), \mathrm{y} 2(\mathrm{t}), \mathrm{t}=0 . .1]$, color=green, thickness=1, scaling=CONSTRAINED):

$>\mathrm{k} 2$ _poligon:=plot $(\mathrm{k} 2$,scaling=CONSTRAINED $)$ :

$>\operatorname{display}(\{$ egri2,k2_poligon $\})$ :

olup, bu programın çalıştırılması ile elde edilen ve sağ partiyi temsil eden Rasyonel Bézier eğrisinin parametrik denklemleri; 


$$
\begin{aligned}
& x(t)=\frac{a_{1}(1-t)^{51}+a_{2} t(1-t)^{50}+a_{3} t^{2}(1-t)^{49}+\ldots+a_{50} t^{50}(1-t)+a_{51} t^{51}}{b_{1}(1-t)^{51}+b_{2} t(1-t)^{50}+b_{3} t^{2}(1-t)^{49}+\ldots+b_{50} t^{50}(1-t)+b_{51} t^{51}} \\
& y(t)=\frac{c_{1}(1-t)^{51}+c_{2} t(1-t)^{50}+c_{3} t^{2}(1-t)^{49}+\ldots+c_{50} t^{50}(1-t)+c_{51} t^{51}}{d_{1}(1-t)^{51}+d_{2} t(1-t)^{50}+d_{3} t^{2}(1-t)^{49}+\ldots+d_{50} t^{50}(1-t)+d_{51} t^{51}}
\end{aligned}
$$

şeklinde bulunmuş ve bu denklemlerin oluşturduğu eğrinin grafiği Şekil 8'de verilmiştir. Burada katsayılar oldukça büyük reel sayılardan oluşması nedeniyle $a_{1}, a_{2}, a_{3}, \ldots, a_{50}, a_{51}, b_{1}, b_{2}, b_{3}, \ldots, b_{50}$, $b_{51}, c_{1}, c_{2}, c_{3}, \ldots, c_{50}, c_{51}, d_{1}, d_{2}, d_{3}, \ldots, d_{50}$ ve $d_{51}$ şeklinde alfabetik olarak yazımı tercih edilmiştir.

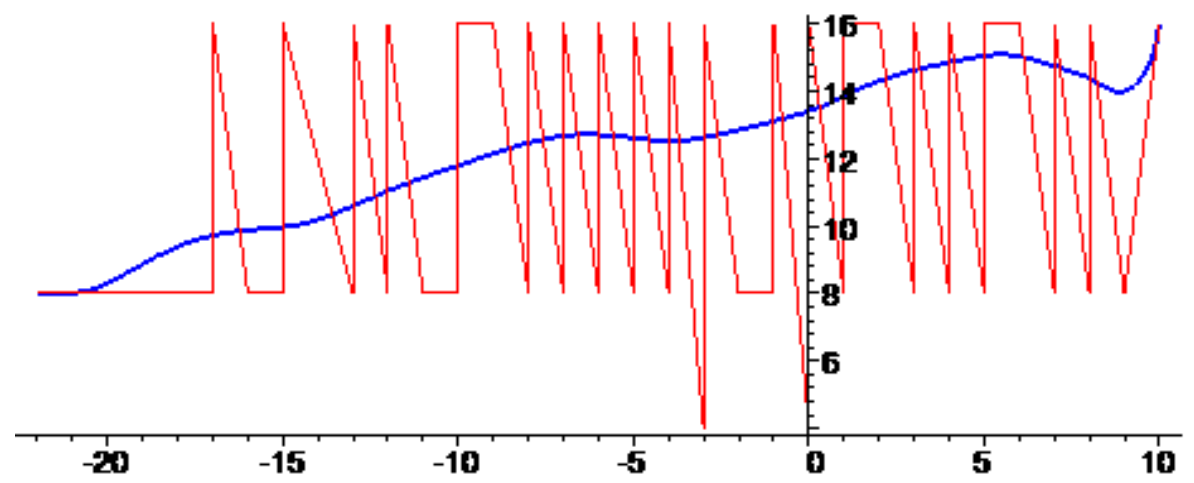

Şekil 8. Bach’ın İki Sesli Envasiyonunun Sağ Partisinin Rasyonel Bézier Eğrisinin Görsel Modeli

Şekil 8'de parametrik denklemleri 51. dereceden birer polinom fonksiyon olan $P(t)=$ $(x(t), y(t))$ ile tanımlı Rasyonel Bézier eğrisinin grafiği çizilmiştir. Bu eğrinin $\mathrm{x}$ ekseni tanım aralı̆̆ $[-22,10]$ olan sol el nota yükseklikleri, y ekseni ise sol el ses süreleri ile kodlanmıştır. Bulunan Rasyonel Bézier eğrisinin grafiği aracılığıyla eserin sağ partisinin görsel modeli oluşturulmuştur. Bu modelle de eserin sağ partisinin [1,10] aralı̆̆ında kullanılan tiz seslerin $[-22,-1]$ aralığında pes seslere daha az kullanıldığı tespit edilmiştir.

$>$ \#Sağ-Sol El

Envansiyonun sağ ve sol partilerinin maple programı;

$>\mathrm{k} 3:=\operatorname{Matrix}([[-22,8],[-21,8],[-20,8],[-19,8],[-17,8],[-17,16],[-16,8],[-15,8],[-15,16],[-13,8],[-13,16],[-12,8],[-$ $12,16],[-11,8],[-10,8],[-10,16],[-9,16],[-8,8],[-8,16],[-7,8],[-7,16],[-6,8],[-6,16],[-5,8],[-5,16],[-4,8],[-4,16],[-$ $3,4],[-3,8],[-3,16],[-2,8],[-1,8],[-1,16],[0,4],[0,8],[0,16],[1,8],[1,16],[2,16],[3,8],[3,16],[4,8],[4,16]$, $[5,8],[5,16],[6,8], \quad[6,16], \quad[7,8],[7,16],[8,8],[8,16],[9,8],[9,16],[10,8],[10,16],[12,8],[12,16],[13,8],[13,16]$, $[14,16],[15,8],[15,16],[16,16],[17,8],[17,16],[18,8],[18,16],[19,8],[19,16],[20,8],[20,16],[21,16],[22,8]$, $[22,16],[23,16],[24,8],[24,16],[25,8],[25,16]]):$

> w3:=Matrix([2,2,4,2,1,3,4,7,2,8,4,7,5,1,5,5,1,10,13,3,4,3,6,4,13,9,2,3,7,21,2,7,17,4,10,21,9,28,1,3,19,1,3,7,38,

$2,11,1,9,4,14,4,7,4,27,3,32,8,33,2,3,34,4,9,24,1,12,2,5,5,10,1,1,5,1,1,2,1,1])$ :

$>\mathrm{m}, \mathrm{n}:=\operatorname{Dimen} \operatorname{sion}(\mathrm{k} 3)$ :

$>\mathrm{b}:=\mathrm{m}-1: \mathrm{x}:=0: \mathrm{y}:=0$ :binomx: $=0$ :binomy: $=0$ :

$>$ for $\mathrm{i}$ from 0 to $\mathrm{b}$ do

$>\mathrm{x}:=\mathrm{x}+\mathrm{w} 3[1, \mathrm{i}+1] * \operatorname{binomial}(\mathrm{b}, \mathrm{i}) *\left(\mathrm{t}^{\wedge} \mathrm{i}\right) *(1-\mathrm{t})^{\wedge}(\mathrm{b}-\mathrm{i}) * \mathrm{k} 3[\mathrm{i}+1,1]$ :

$>\mathrm{y}:=\mathrm{y}+\mathrm{w} 3[1, \mathrm{i}+1]^{*} \operatorname{binomial}(\mathrm{b}, \mathrm{i})^{*}\left(\mathrm{t}^{\wedge} \mathrm{i}\right)^{*}(1-\mathrm{t})^{\wedge}(\mathrm{b}-\mathrm{i})^{*} \mathrm{k} 3[\mathrm{i}+1,2]:$

$>$ binomx:=binomx $+\mathrm{w} 3[1, \mathrm{i}+1]^{*} \operatorname{binomial}(\mathrm{b}, \mathrm{i})^{*}\left(\mathrm{t}^{\wedge} \mathrm{i}\right)^{*}(1-\mathrm{t})^{\wedge}(\mathrm{b}-\mathrm{i})$ :

$>$ binomy:=binomy+w3 $[1, \mathrm{i}+1] * \operatorname{binomial}(\mathrm{b}, \mathrm{i}) *\left(\mathrm{t}^{\wedge} \mathrm{i}\right)^{*}(1-\mathrm{t})^{\wedge}(\mathrm{b}-\mathrm{i})$ :

$>$ end do:

$>\mathrm{x} 3:=\mathrm{x} /$ binomx:

$>\mathrm{y} 3:=\mathrm{y} /$ binomy:

$>$ egri3:=plot $([\mathrm{x} 3(\mathrm{t}), \mathrm{y} 3(\mathrm{t}), \mathrm{t}=0 . .1]$, color=blue, thickness=2, scaling=CONSTRAINED):

$>\mathrm{k} 3$ _poligon:=plot $(\mathrm{k} 3$, scaling=CONSTRAINED $)$ :

$>$ display( $\{$ egri3,k3_poligon $\})$; 
olup, bu programın çalıştırılması ile elde edilen ve tüm partileri temsil eden Rasyonel Bézier eğrisinin parametrik denklemleri;

$$
\begin{aligned}
& x(t)=\frac{a_{1}(1-t)^{78}+a_{2} t(1-t)^{77}+a_{3} t^{2}(1-t)^{76}+\ldots+a_{77} t^{77}(1-t)+a_{78} t^{78}}{b_{1}(1-t)^{78}+b_{2} t(1-t)^{77}+b_{3} t^{2}(1-t)^{76}+\ldots+b_{77} t^{77}(1-t)+b_{78} t^{78}} \\
& y(t)=\frac{c_{1}(1-t)^{78}+c_{2} t(1-t)^{77}+c_{3} t^{2}(1-t)^{76}+\ldots+c_{77} t^{77}(1-t)+c_{78} t^{78}}{d_{1}(1-t)^{78}+d_{2} t(1-t)^{77}+d_{3} t^{2}(1-t)^{76}+\ldots+d_{77} t^{77}(1-t)+d_{78} t^{78}}
\end{aligned}
$$

şeklinde bulunmuş ve bu denklemlerin oluşturduğu eğrinin grafiği Şekil 9'da verilmiştir. Burada katsayılar oldukça büyük reel sayılardan oluşması nedeniyle $a_{1}, a_{2}, a_{3}, \ldots, a_{77}, a_{78}, b_{1}, b_{2}, b_{3}, \ldots, b_{77}$, $b_{78}, c_{1}, c_{2}, c_{3}, \ldots, c_{77}, c_{78}, d_{1}, d_{2}, d_{3}, \ldots, d_{77}$ ve $d_{78}$ şeklinde alfabetik olarak yazımı tercih edilmiştir.

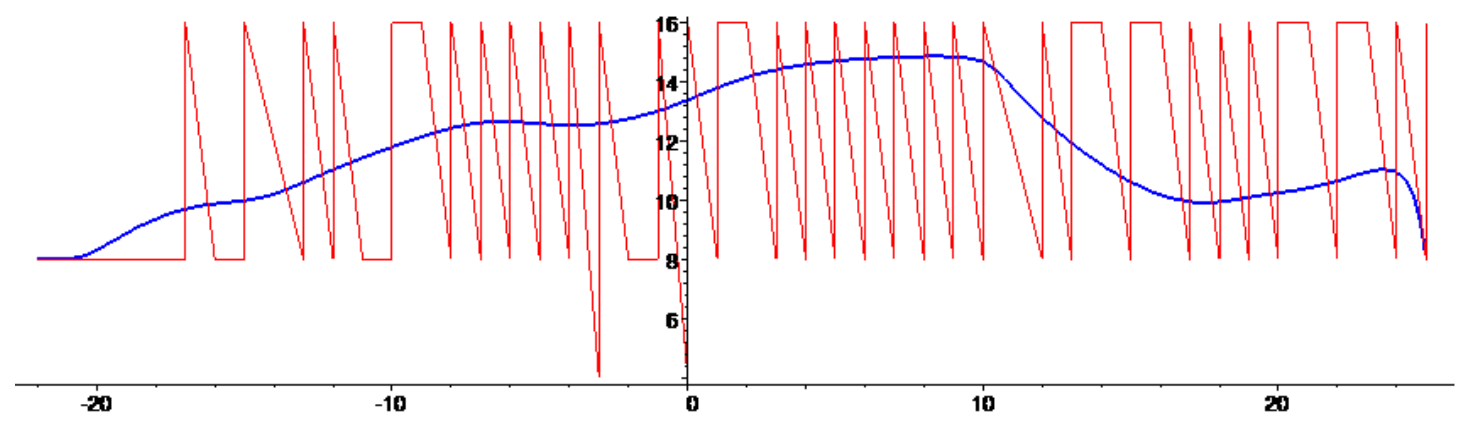

Şekil 9. Bach’ın İki Sesli Envasiyonunun Sağve sol Partilerinin Rasyonel Bézier Eğrisinin Görsel Modeli

Şekil 9'da parametrik denklemleri 78. dereceden birer polinom fonksiyon olan $P(t)=$ $(x(t), y(t))$ ile tanımlı Rasyonel Bézier eğrisinin grafiği çizilmiştir. Bu eğrinin $\mathrm{x}$ ekseni tanım aralı̆ğ $[-22,25]$ olan sol el nota yükseklikleri, y ekseni ise sol el ses süreleri ile kodlanmıştır. Bulunan Rasyonel Bézier eğrisinin grafiği aracılığıyla eserin sol partisinin görsel modeli oluşturulmuştur. Bu modelle de eserin sol partisinin pes sesleri temsil eden $[-22,-1]$ aralığında artarak seyreder iken tiz seslerin yer aldığ $[1,25]$ aralıkta daha stabil olduğu tespit edilmiştir.

\section{Sonuç}

Matematik ve müzik, bilimin ve sanatın iki önemli disiplinidir. Bu iki disiplin antik devirlerden itibaren karşılaştırılmış ve ilişkilendirilmiştir. Matematiğin iç disiplininde ve uyumunda estetik ve güzellik vardır. Matematikte işlemler arasında renkler, notalar ve sözcükler gibi uyumlu bir düzen bulunmaktadır. Problemin ya da teoremin ispatındaki orijinallik, sıra dışılık ve çözüme ulaşabilme deki düşünme şekli matematiğin estetiğidir. Matematiğin estetiğini rahatlıkla fark edilebilecek bu çalışmada J.S. Bach'ın piyano için yazdığı BWV 784 la minör iki sesli envansiyonunu meydana getiren seslerin matematiksel kodlama yoluyla Rasyonel Bézier eğrileri kullanılarak görsel modeli oluşturulmuştur. Rasyonel Bézier Eğri parametrik denkleminde ses yükseklikleri, ses değerleri ve frekans değerleri olarak kullanılmış ve buna bağlı müzik eserinin sağ ve sol partilerini temsil eden polinom fonksiyonların grafikleri çizilmiştir. Bu polinomların grafikleri ile eserin görsel modeli elde edilmiştir. Çizilen bu grafikler eserinin ses yükseklikleri ile süre değerleri ve kullanım sayılarına göre eserin görsel modelini oluşturmuştur.

\section{Yazarların Katkısı}

Yazarların makaleye katkısı eşittir. 


\section{Çıkar Çatışması Beyanı}

Yazarlar arasında herhangi bir çıkar çatışması bulunmamaktadır.

\section{Araştırma ve Yayın Etiği Beyanı}

Yapılan çalışmada, araştırma ve yayın etiğine uyulmuştur.

\section{Kaynaklar}

[1] Battey B. 2004. Bézier spline modeling of pitch-continuous melodic expression and ornamentation. Computer Music Journal, 28 (4): 25-39.

[2] Bigerelle M., Alain I. 2000. Fractal dimension and classification of music. Chaos Solitons \& Fractals, 11: 2179-2192.

[3] Büke A. 2005. Bach Yaşamı ve Eserleri. Kabalcı Yayınevi, İstanbul.

[4] Büke A., Altınel İ.M. 2006. Müziği Yaratanlar Barok Dönem. Globous Dünya Basımevi, İstanbul.

[5] Campbell P. 1986. The music of digital computers. Nature, 324: 523-528.

[6] Devlin K. 2000. The math gene: How mathematical thinking evolved and why numbers are like gossip. Basic Books. Great Britain.

[7] Dönmez B.M., Atan A. 2016. Johann Sebastian Bach'ın Klavsen Eserlerinde Anlatım Üslubu. İnönü Üniversitesi Sanat ve Tasarım Dergisi, 6 (13): 211-233.

[8] Farin G. 1997. Curves and Surfaces for Computer-Aided Geometric Design. Academic Press, London.

[9] Feridunoğlu L. 2004. Müziğe Giden Yol, İnkılap Yayınevi. İstanbul.

[10] Gökler M. 2015. Bilgisayarda Geometrik Modelleme. ODTÜ Makina Mühendisliği, ODTÜ CAD/CAM Merkezi.

[11] Guerino M. 2002. The Topos of Music: Geometric Logic of Concepts, Theory, and Performance. Birkhauser Verlag, Basel, Boston, Berlin.

[12] Koshy T. 2001. Fibonacci and Lucas Numbers with Applications. Wiley-Interscience Publication, Canada.

[13] Lehmann I., Alfred P. 2007. The (Fabulous) Fibonacci Numbers. Prometheus Books, New York.

[14] Orhan C. 1995. Matematik ve Müzik. Matematik Dünyası, 5 (1): 6-7.

[15] Rehding. A. 2003. Hugo Riemann and the birth of Modern Musical Thought. Cambridge University Press. London.

[16] Riedweg C. 2005. Pythagoras: His Life, Teaching and Influence. Cornell University Press. New York.

[17] Rogers D.F, Adams J.A. 1990. Mathematical Elements for Computer Graphics. McGraw-Hill Publishing, New York.

[18] Stolzenburg F. 2009. A Periodicity-Based Theory for Harmony Perception and Scales. Proceedings of the 10th International Society for Music Information Retrieval Conference, pp8792, October 26-30, Kobe, Japan.

[19] Wright D. 2009. Mathematics and Music. American Mathematical Society, USA.

[20] Schroeder H. 1994. Fractele, Chaos und Selbstahnlichkeit: Spektrum Akademischer Verlag, Berlin.

[21] Demirbatır R.E., Yağcı F., Ezentaş R. 2018. Matematiksel Kodlama Yoluyla A. Adnan Saygun'un “İnci” Adlı Piyano Parçasının Geometrik Modellemesi. Uluslararası Necatibey Egitim ve Sosyal Bilimler Arastırmaları Kongresi, Tam Metin Bildiri Kitab1, pp483-492, 26-28 Ekim 2018, Balıkesir. 